\title{
Verdad científica, poder y obediencia
}

\section{César Cárcamo Quezada ${ }^{1}$}

Resumen: La creencia por parte de los médicos de una objetividad sin paréntesis, que asume, por un lado, una existencia real de la verdad científica y, por otro, les confiere la posibilidad de conocer dicha verdad prescindiendo de su subjetividad, determina que ciertas relaciones médico-paciente sean relaciones de poder y obediencia, en las cuales la obediencia se justifica por promesas de medios y resultados, promesas fundadas a su vez en la creencia de que poseen acceso a una verdad objetiva con independencia de lo que hacen. Basados en la teoría del conocimiento de Humberto Maturana, cuestionamos ese paradigma y, a la luz de la biología, proponemos una nueva mirada al conocimiento objetivo.

Palabras clave: relación médico-paciente, conocimiento, medicina basada en evidencias, práctica basada en evidencias

\section{Scientific truth, power and obedience}

\begin{abstract}
Physicians belief in objectivity without parenthesis, which assumes, in one side, the real existence of scientific truth and, in the other, confers the possibility of knowing such truth leaving aside subjectivity, which determines that certain physician-patient relations are of power and obedience, in which obedience is justified by promises of means and results, promises based in the belief of having access to an objective truth independent from actions taken. Based in the theory of knowledge of Humberto Maturana, we question this paradigm and, under biological insight, we propose a new look to objective knowledge.
\end{abstract}

Key words: physician-patient relation, knowledge, evidence based medicine, practice based on evidences

\section{Verdade científica, poder e obediência}

Resumo: A crença por parte dos médicos de uma objetividade sem parênteses, que assume, por um lado, uma existência real da verdade científica e, por outro, lhes confere a possibilidade de conhecer a dita verdade prescindindo de sua subjetividade, determina que certas relaçóes médico-paciente sejam relaçôes de poder e obediência, nas quais a obediência se justifica por promessas de meios e resultados, promessas fundadas, por sua vez, na crença de que possuem acesso a uma verdade objetiva com independência do que fazem. Baseados na teoria do conhecimento de Humberto Maturana, questionamos esse paradigma e, à luz da biologia, propomos um novo olhar sobre o conhecimento objetivo.

Palavras-chave: relação médico-paciente, conhecimento, medicina baseada em evidências, prática baseada em evidencias

\footnotetext{
${ }^{1}$ Profesor del Centro de Negociación, Escuela de Negocios, Universidad Adolfo Ibáńez, Chile

Correspondencia: ccarcamo@mutual.cl
} 


\section{Introducción}

A los médicos nos gusta decir que somos científicos y que, como tales, somos poseedores de verdades científicas. Esta creencia de una objetividad sin paréntesis, que confiere al médico científico la posibilidad de conocer prescindiendo de su subjetividad, determina que ciertas relaciones médicopaciente sean relaciones de poder y obediencia, en las cuales la obediencia se justifica por promesas de medios y resultados, promesas fundadas a su vez en la creencia de que el médico tiene acceso a una verdad objetiva con independencia de lo que hace.

En este ensayo, basado en la teoría del conocimiento de Humberto Maturana(1-11), invitamos a poner la objetividad, la verdad científica, entre paréntesis, y a darnos cuenta de que, como los médicos no podemos hacer referencia a algo real, independiente de nosotros, para validar y justificar nuestro explicar y operar, toda afirmación cognoscitiva se transforma en una invitación a participar, junto con los pacientes, en un cierto dominio de experiencias. Y en este camino nos hacemos responsables por lo que decimos y hacemos, pues lo que hacemos valida lo que decimos en ese dominio de coherencias experienciales.

\section{El poder de los médicos}

A través de su modo particular de operar, cada sistema social otorga a determinadas personas poder para definir la normalidad o anormalidad, la salud o la enfermedad, otorgándoles el derecho a ser escuchados y obedecidos en estos dominios. En nuestra cultura occidental actual este poder o autoridad se nos otorga socialmente a los médicos, bajo la suposición de que poseemos un conocimiento objetivo que nos capacita para distinguir a los sanos de los enfermos. Más aún, esta autorización social para hacer diagnósticos de patologías bajo el argumento de que poseemos un conocimiento objetivo, es de hecho una concesión social de poder que, al permitirnos exigir obediencia a nuestras prescripciones, cualesquiera que estas sean, porque están fundadas en un conocimiento trascendente de la verdad, nos permite usar nociones de conocimiento objetivo como modos legítimos y adecuados para tratar con las personas que han sido objeto de nuestro diagnóstico.

\section{El conocimiento científico como verdad}

Los médicos, como científicos, vivimos en un mundo que distinguimos como un mundo de problemas y de explicaciones de los problemas. Tenemos la experiencia de los problemas y lo que hacemos como científicos es proponer como explicación o causa aceptable de un problema algo que describe un mecanismo que produce esa situación o problema como consecuencia de su operación.

Maturana propone que cuando decimos y afirmamos que la explicación o causa aceptable de un problema está "allí afuera", con independencia de lo que hacemos, se trata de una "objetividad sin paréntesis" (7-9), postura de la objetividad tradicional que asume, por un lado, una existencia real de las explicaciones y, por otro, confiere al médico científico la posibilidad de conocer los objetos prescindiendo de su subjetividad.

Maturana llama a este camino explicativo el de la objetividad sin paréntesis porque allí los científicos se conducen como si hubiesen explicaciones cuya existencia es independiente de lo que hacen ("están ahí fuera”) y solo requieren formas o procedimientos para encontrarlas, tales como la medicina basada en evidencias, y que pueden señalar y traer a la mano para validar y justificar su actuar.

Así, bajo la noción explícita o implícita de que el conocimiento objetivo es una base adecuada para fundamentar la autoridad social en el dominio de la salud, los médicos definimos lo que ocurre a otras personas por medio del diagnóstico y la determinación del tratamiento desde la posición "objetiva" de quien posee un acceso privilegiado a una realidad independiente.

\section{Las bases del poder}

El poder social que se nos otorga a los médicos se basa en la suposición de que tenemos acceso a una realidad objetiva y que es nuestro conocimiento de dicha realidad objetiva el que le da validez a nuestras acciones clínicas. De hecho, 
todo nuestro entrenamiento, tanto en términos de información como de experiencia práctica, nos lleva a creer que es así. Por eso actuamos como si nuestras dificultades en el conocer y en el ser efectivos tuvieran que ver solo con la dificultad para encontrar la representación más verdadera y exacta de esa realidad objetiva e independiente, pero que una vez que la encontremos no habría espacio para el error.

\section{Múltiples teorías, múltiples explicaciones}

Dado que los médicos creemos que en la actualidad conocemos solo parte de la realidad, y que existen vastas áreas de ella que ignoramos, y que es esta ignorancia la que da lugar a las distintas corrientes de pensamiento, teorías y modelos, no se nos ocurre pensar que esta diversidad de teorías - y, sobre todo, la diversidad de las prácticas efectivas: "la variabilidad de la práctica clínica" - revela que la suposición de que a través del conocimiento tenemos acceso a una realidad independiente y objetiva es inadecuada, y que el fenómeno del conocer es algo diferente. En efecto, la propuesta de Maturana(1-11) es que podemos tomar el desacuerdo acerca de cómo son las cosas como una revelación de que el fenómeno del conocer o del conocimiento surge en las distinciones que el observador realiza a medida que trae a la mano lo distinguido a través de su operar en el lenguaje, más que en la captación de una entidad independiente.

El acceso a "la mejor información científica disponible" está llena de sesgos, que no son otra cosa que distinciones particulares basadas en la experiencia subjetiva de cada médico.

\section{Verdad objetiva y sesgo de publicación}

En efecto, en medicina basada en evidencias se entiende por "sesgo de publicación" la tendencia por parte de las revistas a publicar estudios con resultados positivos y a rechazar los no significativos.

Es este un sesgo bien conocido, pero es fácil que pase desapercibido. A la hora de enfrentarse a la lectura crítica de una revisión sistemática de ensa- yos clínicos se ha de tener en cuenta si sus autores hicieron todos los esfuerzos posibles por minimizar la posible presencia de este sesgo, mediante estrategias que permitan la recuperación de estudios no publicados (mediante contacto con expertos, con la industria farmacéutica, búsqueda en literatura gris). Aun con todo, la posibilidad de dicho sesgo está ahí. El origen puede estar en la propia revista (tendencia de su equipo editorial a publicar estudios con resultados positivos), en los propios autores del artículo ("si la p no sale significativa el estudio no interesa”), en la posible fuente de financiación (que puede facilitar la publicación de estudios favorables a determinados productos y "silenciar" otros que no han dado los resultados deseados) o en el "prestigio" de la institución que lo promueve (mayor facilidad para que un estudio se publique si está elaborado en un centro sanitario bien considerado, independientemente de los resultados del mismo). El sesgo de publicación puede verse agravado, en el caso de las revisiones sistemáticas, si estas se centran en recuperar estudios escritos únicamente en inglés, fenómeno muy frecuente y extendido en muchas revistas especialmente anglosajonas ("lo que no está en inglés no existe"). Algunos autores cuyo idioma no es el inglés suelen intentar publicar sus estudios con resultados positivos en revistas en inglés, ya que estas poseen mayor impacto internacional y los estudios con resultados negativos tienden a publicarse en revistas en otros idiomas diferentes al inglés(12).

Luego, ¿es posible afirmar todavía que las explicaciones científicas que nos damos y validamos se construyen con independencia de nuestra subjetividad?

Si no es así, ¿qué deberíamos entender por objetividad entonces? ¿Existiría una "objetividad sin paréntesis"?

\section{La objetividad entre paréntesis}

Maturana afirma que si nos damos cuenta de que en la experiencia no podemos distinguir entre ilusión y percepción, de que un conjunto de observadores tampoco puede hacer tal distinción y de que esta es una condición propia de un observador como ser vivo, entonces no podríamos pretender 
que podemos validar nuestro explicar haciendo referencia a una realidad externa e independiente de nosotros y de nuestro quehacer como observadores(1-11). Señala a este darse cuenta y operar como observadores de una manera concordante con este darse cuenta como "poniendo la objetividad entre paréntesis”. El paréntesis indicaría, al decir de Maturana, que "nos damos cuenta de que no podemos hacer referencia a una realidad independiente de nosotros para validar nuestro explicar y no lo haremos. Al mismo tiempo, nos haremos cargo de que al dar explicaciones a los problemas de los pacientes, explicamos los problemas con elementos de nuestra experiencia, de nuestra subjetividad, en circunstancias de que no podemos distinguir, en la experiencia, entre ilusión y percepción".

Al hacer esto, nos damos cuenta, además, de que al aceptar que no podemos hacer esa referencia generamos múltiples dominios de explicaciones, todos los cuales los vivimos como existiendo con independencia de nosotros, pero con conciencia de que esas explicaciones surgen en nuestro explicar nuestra experiencia y no ocurren con independencia de lo que hacemos.

Las explicaciones científicas que nos damos y validamos no se construyen con independencia de nuestra experiencia, única y distinta para cada uno de nosotros. La verdad científica que nos damos y validamos la construimos sobre la base de nuestra experiencia subjetiva.

Invitación a una nueva relación médico-paciente

$\mathrm{Al}$ poner la objetividad entre paréntesis y darnos cuenta de que no podemos hacer referencia a algo real independiente de nosotros para validar nuestro explicar, toda afirmación cognoscitiva se transforma en una invitación a participar en un cierto dominio de experiencias. Y en este camino el médico se hace responsable por lo que hace, pues lo que hace valida lo que dice en ese dominio de coherencias experienciales.

Cuando se pone la objetividad entre paréntesis, el desacuerdo desaparece como tal, porque las partes se dan cuenta que los diferentes puntos de vista son válidos en los distintos dominios, ya que se fundan en premisas diferentes, y emerge la humildad y la aceptación mutua. Con la objetividad entre paréntesis el punto en cuestión ya no es más quién tiene la razón o quién se equivoca, sino si queremos o no coexistir en una relación social médico-paciente, o si queremos o no las consecuencias de vivir una determinada realidad. Si queremos coexistir debemos encontrarnos en un dominio común en el que compartamos las premisas que lo definen, y donde los puntos de vista en conflicto no intervengan o sus consecuencias se vuelvan irrelevantes.

Con la objetividad entre paréntesis, la necesidad de imponer el punto de vista personal sobre el del otro, destruyéndolo en ese dominio, desaparece, y cada uno de nosotros se vuelve responsable de sus preferencias y deseos, porque ellos constituyen el fundamento de sus construcciones racionales.

En la objetividad entre paréntesis no hay necesidad de negación mutua, porque no hay necesidad de defenderse, y existe conciencia tanto de que solo se superará el desacuerdo mediante la coexistencia en otro dominio de distinciones donde éste no surja, como de que se puede coexistir en ella solo si hay una sincera voluntad y deseo de coexistencia.

Las relaciones médico-paciente que se ponen en juego son totalmente distintas en uno y en otro caso. Por ello, frente a las relaciones médico-paciente basadas en la creencia de un acceso privilegiado a una verdad objetiva y trascendente, que determinan un dominio de relaciones de poder y obediencia, en el cual el error médico y los eventos adversos son un quiebre de una promesa de medios y resultados que determina castigo y reparación, proponemos una relación médicopaciente como una relación social en la cual la sincera disculpa y el perdón sean legítimas conversaciones en el dominio de los eventos adversos y los errores. 


\section{Referencias}

1. Maturana H. Biología de la cognición y epistemología. Temuco: Ed. Universidad de la Frontera; 1990.

2. Maturana H, Ludewig K. Conversaciones con Humberto Maturana: Preguntas del psicoterapeuta al biólogo. Temuco: Ed. Universidad de la Frontera; 1992.

3. Maturana H. El sentido de lo humano. Santiago de Chile: Editorial Dolmen; 1992.

4. Maturana H, Verden-Zoller G. Amor y juego: Fundamentos olvidados de lo humano. Colección Experiencia Humana. Ed. Instituto de Terapia Cognitiva; 1993.

5. Maturana H. Desde la biología a la psicología. $1^{a}$ ed. SYNTHESIS; 1993.

6. Maturana H. Emociones y lenguaje en educación y politica. $7^{\text {a }}$ ed. Santiago de Chile: Hachette/CED; 1994.

7. Maturana H. La realidad: ¿Objetiva o construida? I. Fundamentos biológicos de la realidad. $1^{\text {a }}$ ed. Barcelona: Anthropos; 1995.

8. Maturana H. La realidad: ¿Objetiva o construida? II. Fundamentos biológicos del conocimiento. $1^{\text {a }}$ ed. Barcelona: Anthropos; 1995.

9. Maturana H. La objetividad: un argumento para obligar. $1^{\text {a }}$ ed. Santiago de Chile: Dolmen; 1997.

10. Maturana H, Pörksen B. Del ser al hacer: los orígenes de la biología del conocer. $1^{\text {a }}$ ed. Santiago de Chile: JC Sáez; 2007.

11. Dávila X, Maturana H. Habitar humano en seis ensayos de biología cultural. $1^{\text {a }}$ ed. Santiago de Chile: JC Sáez; 2008.

12. Hopewell S, Loudon K, Clarke MJ, Oxman AD, Dickersin K. Publication bias in clinical trials due to statistical significance or direction of trial results. Cochrane Database of Systematic Reviews 2009; 1. Art. No MR000006. DOI: 10.1002/14651858.MR000006. pub3.

Recibido: 16 de enero de 2010

Aceptado: 30 de marzo de 2010 